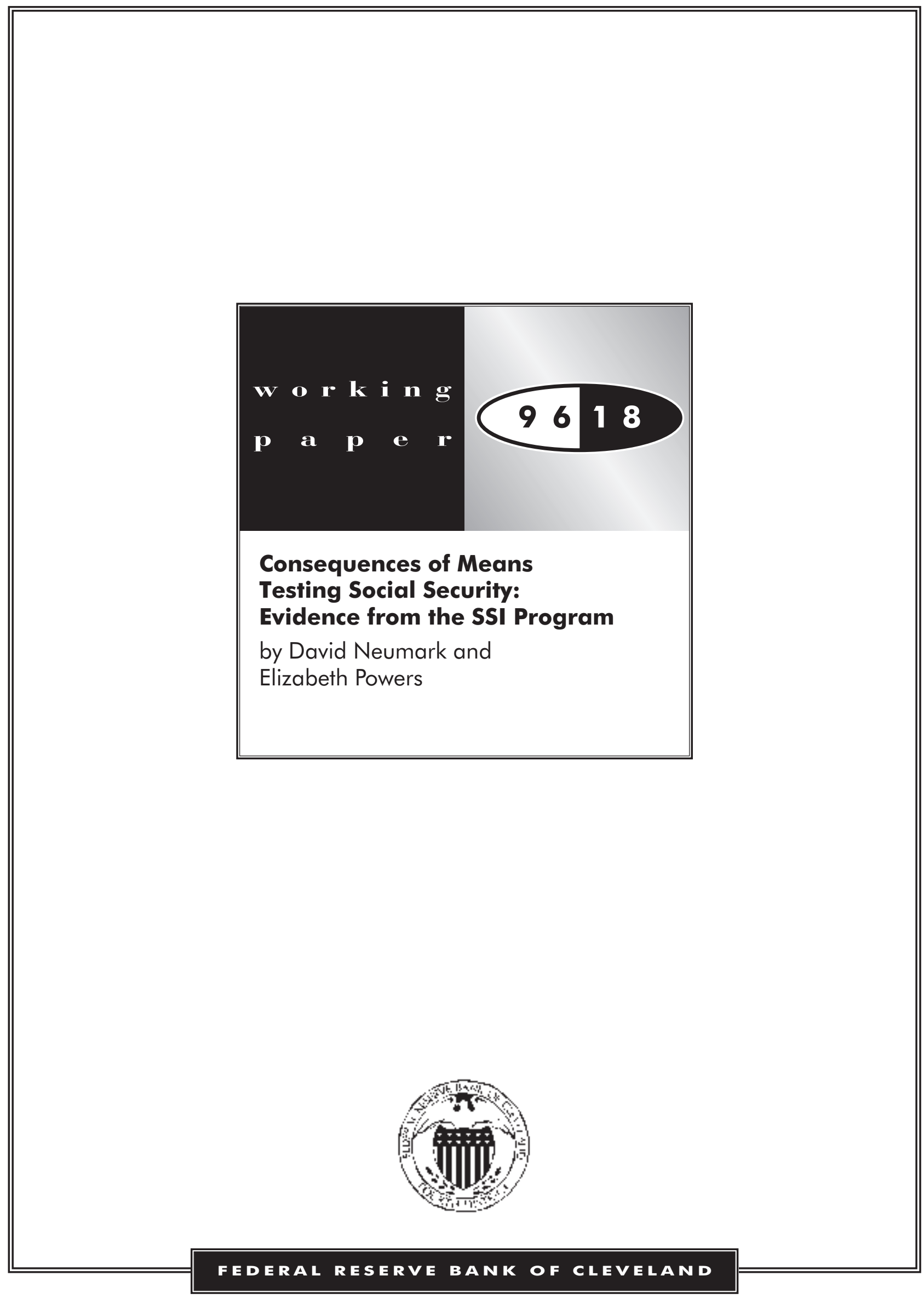


CONSEQUENCES OF MEANS TESTING SOCIAL SECURITY:

EVIDENCE FROM THE SSI PROGRAM

David Neumark and Elizabeth Powers*

November 1996

"Neumark is Professor of Economics at Michigan State University, and a Research Associate of the NBER. Powers is an Assistant Professor of Economics at the University of Illinois. Neumark was a Visiting Scholar at the Federal Reserve Bank of Cleveland (FRBC), and Powers was an Economist at the FRBC, during the period when this research was conducted. Neumark gratefully acknowledges support from NIA grant K01-AG00589. We are grateful to seminar participants at the Cleveland Fed and Michigan State University, and to Paul Menchik and Mark Schweitzer, for helpful comments. 


\title{
CONSEQUENCES OF MEANS TESTING SOCIAL SECURITY: EVIDENCE FROM THE SSI PROGRAM
}

\begin{abstract}
$\underline{\text { Abstract }}$
We attempt to draw inferences about the potential behavioral responses to means testing Social Security by examining the effects of the Supplementary Security Income (SSI) program for the aged on wealth accumulation and employment. Part of the SSI program provides payments to the poor elderly, thus operating as a means-tested public retirement program. The federal government sets eligibility criteria and benefit levels for the federal component of the program, but many states supplement federal SSI benefits substantially.

We exploit the state-level variation in SSI benefits to estimate the effects of SSI on saving and labor supply. We use data from waves 4, 5, and 7 of the Survey of Income Program Participation (SIPP), covering individuals in the 1983-1986 period. We find evidence that high SSI benefits reduce saving among households with male heads who are approaching the age of eligibility for SSI for the aged, and who are likely participants in the program. But we find little consistent evidence that generous SSI benefits reduce the labor supply of older men nearing the age of eligibility. This evidence suggests that a means-tested Social Security program that bases eligibility or payment levels in part on accumulated wealth may, consistent with the fears of critics of such a program, discourage saving among those approaching the age of retirement.
\end{abstract}




\section{Introduction}

The large projected increases in benefit payments as the baby boom cohort approaches retirement have spurred interest by policy makers and researchers alike in proposals to reform the Social Security system. Broadly speaking, three types of proposals receive most of the attention. The first is to "tinker" with the existing system by such means as increasing the retirement age or indexing benefits to a price index that rises more slowly than the CPI. The second is to switch from an unfunded system to a fully or partially privatized, fully-funded system. The third is to convert Social Security from a universal entitlement program to a means-tested program that would pay benefits (or perhaps full benefits) only to those who lack sufficient assets or post-retirement income to finance retirement (Bipartisan Commission on Entitlement and Tax Reform, 1995). ${ }^{1}$ A small means-tested program might also be a component of a largely privatized system (Mitchell and Zeldes, 1995).

Evaluation of these alternative types of proposals rests in large part on their effects on revenues and costs, as well as saving and labor supply (which in turn affect revenues and costs). There is an extensive literature that attempts to estimate the effects of changing various parameters of the Social Security system (e.g., Gustman and Steinmeier, 1984, 1986, and 1991; Burtless and Moffitt, 1985). This literature frequently relies on variation in program parameters across time or across individuals to identify the effects of interest. There is a newer but burgeoning literature that considers the effects of a privatized Social Security system (e.g., Altig and Gokhale, 1996; Arrau and Schmidt-Hebbel, 1993; Feldstein, 1995; Gustman and Steinmeier, 1995; Kotlikoff, 1995; Mitchell and Zeldes, 1996). ${ }^{2}$ Research on this latter question is plagued, of course, by the absence of past experience with a privatized system, and hence tends

\footnotetext{
${ }^{1}$ In the report of the Bipartisan Commission, Commissioner Peter G. Peterson (with support from Commissioner Robert E. Denham) proposes applying an "affluence test" to all entitlement programs, including Social Security. This proposal is also advocated by the Concord Coalition. The affluence test would apply to payments from all federal benefit programs, and would impose a ten-percent marginal tax rate on benefits for those earning \$40,000-49,999, with the marginal tax rate higher by ten percentage points for each additional $\$ 10,000$ of income. The maximum benefit reduction would be 85 percent.

${ }^{2}$ For recent reviews of these two types of approaches to social security
} 
to rely more on theoretical and simulation methods, as well as discussion of privatization schemes in other countries, most notably Chile. ${ }^{3}$ Research on the consequences of means-testing Social Security faces a similar problem, because the program was never means-tested in the past. Consequently, evaluations of the benefits and costs of means testing hinge on the unknown effects of such a system.

In addition to reducing projected costs sharply, a potential advantage of means-testing Social Security is that it would limit the size of the program, and therefore reduce the distortionary effects of the taxes that are used to finance Social Security. This reduction in distortions is most likely to occur if the conversion from universal to means-tested Social Security does not introduce additional adverse behavioral incentives. In addition, means testing allows for better targeting of benefits to those most in need.

However, as Feldstein (1987) points out, means testing of Social Security may induce other behavioral responses that offset some of the intended benefits of means testing. In particular, if future Social Security benefits depend on the level of financial assets, some individuals may be less likely to save under a means-tested program. ${ }^{4}$ This view appears to be widely held. In an appendix to the report of the Bipartisan Commission on Entitlement and Tax Reform (1995), a large number of economists and other individuals endorse the statement that "Means testing would tax ... saving by cutting Social Security as income from private saving increases, conveying the message: Don't save or we will punish you for your frugality by denying you Social Security" (p. 112). ${ }^{5}$ This type of response might occur, for example, among individuals approaching retirement age who have accumulated relatively little pension wealth

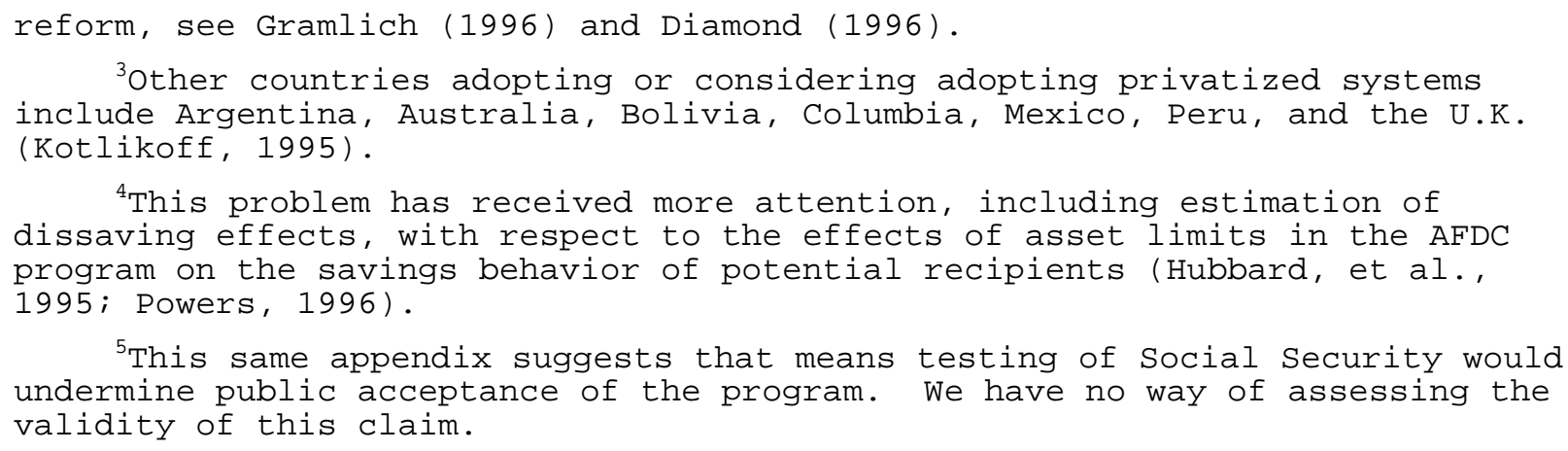


(including Social Security wealth); such workers may do better by saving less (or dissaving) and qualifying for means-tested Social Security, than by saving more and making themselves ineligible, or remaining eligible but with reduced benefits. More generally, the consumption paths of those who choose not to save--entailing higher consumption before retirement, and lower consumption afterwards--may yield higher utility if means-tested Social Security benefits paid to non-savers boost post-retirement consumption sufficiently.

In addition, while savings seems the most obvious place to look for behavioral responses to a means-tested retirement program, such a program may also have effects on labor supply before the age at which an individual would have retired in the absence of such a program. ${ }^{6}$ If benefits under a means-tested system depend in part on the accumulated value of private pensions (possibly as part of a privatized Social Security system for most workers), then means testing may reduce labor supply. For example, workers with accumulated pension wealth sufficiently low to qualify for the means-tested program may face little added incentive to continue working at older ages in order to increase pension wealth (by, for example, increasing covered quarters of Social Security employment), as the extra post-retirement income will be offset against the payments made under the means-tested program, and might make them ineligible. ${ }^{7}$ We think that this influence of a means-tested retirement program is likely to be weaker, because individuals work to satisfy current needs, and not only to accumulate savings for the future; nonetheless, it seems a potential influence worth exploring.

In this paper, we attempt to draw inferences about the potential behavioral responses to means testing Social Security by examining the effects of the Supplementary Security Income (SSI) program for the aged on wealth accumulation and employment. In our view, the SSI program for the aged has many

\footnotetext{
${ }^{6}$ In Feldstein's (1987) analysis, labor supply is treated as exogenous.

${ }^{7}$ With respect to both saving and labor supply, whether or not there are negative wealth effects would ultimately depend on the generosity of a meanstested program compared with the current program. The effects we refer to in this discussion stem from the implicit taxation of savings and pension wealth created by a means-tested system. This issue has parallels to questions regarding the effects of the earnings test for social security.
} 
parallels to the type of means-tested Social Security program that might emerge from serious reform of the existing Social Security system, and hence provides potentially useful information on the effects of meanstesting Social Security. Part of the SSI program provides payments to the poor elderly (aged 65 and over). ${ }^{8}$ The federal government sets eligibility criteria and benefit levels for the federal component of the program. The federal government specifies maximum benefit levels for couples and individuals, which are reduced by income from other sources, including Social Security benefits and Disability Insurance. (The first \$20 of non-means-tested transfer income, the first $\$ 65$ of earned income, plus one-half of remaining earnings, are disregarded in reducing SSI benefits.) Thus, other sources of income influence the potential payments under SSI, and, effectively, eligibility. Financial resources also affect eligibility. For example, as of 1985 , individuals with over $\$ 1600$ in countable assets, and couples with over $\$ 2400$ in countable assets, were ineligible. ${ }^{9}$ In September 1984 (corresponding roughly to the time period covered by our data), there were 1.55 million persons receiving SSI payments who were eligible because of age (1995 Green Book). ${ }^{10}$

While the federal government sets eligibility criteria and benefit levels, states may supplement federal SSI benefits. For example, in January 1985 the maximum federal benefit was $\$ 325$ for an individual, and $\$ 488$ for a couple. The highest state benefit was in California, which resulted in a maximum combined benefit of $\$ 504$ for an individual, and $\$ 936$ for a couple. ${ }^{11}$ In December 1985 the average federal benefit paid was $\$ 146$ for individuals, and \$232 for couples, and the average state supplements were $\$ 97$ and $\$ 257$, respectively (Kahn, 1987), with 39 percent of SSI recipients receiving

\footnotetext{
${ }^{8}$ Unlike Social Security, there is no early retirement option in the SSI program. However, the SSI program also provides benefits to the blind and disabled irrespective of age. We do not consider this component of the program in most of the analysis in this paper.

${ }^{9}$ Kahn (1987) discusses the definition of countable assets, and McGarry (1996) provides more details regarding the SSI program.

${ }^{10}$ Zedlewski and Meyer (1989) estimate that about 30 percent of the elderly poor receive SSI benefits.

${ }^{11}$ If states choose to administer the SSI program, they are also free to set their own eligibility criteria such as asset limits. However, there is little variation in these criteria (Social Security Administration, 1985).
} 
state supplements.

We exploit the state-level variation in SSI benefits to estimate the effects of SSI on savings and labor supply. We use data on male-headed households from waves 4, 5, and 7 of the Survey of Income Program Participation (SIPP), covering individuals in the 1983-1986 period, estimating the effects of state SSI supplements via a difference-in-difference approach that controls for variation in saving profiles across states and across different types of individuals. We find evidence that high SSI benefits reduce saving among households with male heads who are approaching the age of eligibility for SSI for the aged, and who are likely participants in the program. ${ }^{12}$ This evidence is generally robust to a variety of changes in the sample, the specification, or the definition of variables, and the estimated effects generally vary in the expected direction with some of these changes. On the other hand, we find little consistent evidence that generous SSI benefits reduce the labor supply of older men who have characteristics associated with likely participation in SSI. This evidence suggests that a means-tested Social Security program that bases eligibility or payment levels in part on accumulated wealth may, consistent with the fears of critics of such a program, discourage saving among those approaching the age of retirement. In addition to their potential implications for means-testing of Social Security, our findings are also pertinent to understanding the effects of the SSI program itself.

\section{The Data and Empirical Approach}

\section{The Data}

We use a sample drawn from the SIPP, which can be used as a nationally-representative sample of households. The SIPP attempts to gather detailed and reliable data on income and welfare program use that are impractical to collect in the larger Current Population Surveys. Households are interviewed every four months (each four month interval is referred to as a "wave") for two to three years. Most questions are asked retrospectively about the previous four months. However, questions about wealth holdings refer

\footnotetext{
${ }^{12}$ For a wider analysis of the effects on savings behavior of asset limits in various types of welfare programs, see Powers (1995).
} 
to the last day of the month preceding the sample month. This paper uses the first (1984) panel of the SIPP, which covers the period from October 1983 through July 1986. The primary advantage of this panel is that it exceeds the size of the next-largest panel by 27 percent.

Dependent variables for the analyses are SSI participation (for those aged 65 and over), and savings and employment measures (for those aged 40-64). All equations are estimated for various samples of male heads of households (including males living alone). ${ }^{13}$ Since only those aged 65 or over qualify for SSI for the aged, a dummy variable for SSI participation is constructed only for a sample of elderly males, based on participation of the male at any time during wave 4 . Saving is measured as the change in net wealth excluding housing, from wave 4 to wave $7 .{ }^{14}$ This includes all financial assets plus property minus liabilities. Although liabilities are not counted against wealth in determining eligibility for SSI, it is appropriate to subtract them off of the measure we use; because debts can be paid off prior to applying for SSI, the net wealth measure is the most appropriate measure of the assets with respect to which eligibility would be determined. ${ }^{15}$ Corresponding to the definition of counted wealth under SSI, we exclude housing. ${ }^{16}$ We define the variables with which we measure changes in employment a number of different

\footnotetext{
${ }^{13}$ The SIPP actually identifies "householders," who are the individuals in whose name the home is owned or rented. (These are also referred to as "reference persons.") In the case of a married couple owning a house jointly, either the husband or wife can be listed as the householder. The data set documentation provides no guidance as to who is classified as the householder in this case. To avoid selecting males who might be less likely to be classified as heads of household based on other criteria, we selected only records on male householders. In fact, the majority of those receiving SSI for the aged are single women (Kahn, 1987), in part because of greater life expectancy of women.

${ }^{14}$ The data set does not contain imputation flags to identify those observations for which wealth data were imputed. However, we discarded all observations in which the householder was not interviewed in at least one month of the wave. The SIPP weights are adjusted to account for this nonresponse. wealth.

${ }^{16}$ Vehicles are fully exempt from the SSI means test if they are required for medical reasons or employment (and are exempt up to $\$ 4500$ of market value regardless). Because we have no way to test whether this condition is met, we do not exclude the value of respondents' cars. However, the results were very similar when vehicles were excluded.
} 
ways, as discussed below.

Each household is assigned a maximum state SSI benefit based on household composition (whether the household is comprised of an individual or a couple) and state of residence. In the empirical analyses, we sometimes use dummy variables indicating whether the state's benefit exceeds a given percentage of the federal maximum (focusing for the most part on a 20-percent threshold), and at other times we use a continuous measure of the state supplement. The continuous measure uses all of the available information. On the other hand, all we know about individuals prior to age 65 is the maximum benefit available, not the benefit they would actually receive. In addition, the maximum SSI benefits reported in the Green Book are subject to error for some states. For three states (Minnesota, Vermont, and Washington) benefit levels vary by location, and the maximum reported is either for metropolitan areas, in which benefits are presumably higher, or the Green Book explicitly states that the highest level is reported. Since none of these states are classified as paying benefits exceeding 20 percent of the federal level, this measurement problem does not result in misclassification when this particular threshold is used.

Regardless of these considerations, the qualitative results are the same using a continuous measure of maximum benefits or a dummy variable for generous benefits. Appendix Table A1 summarizes the variation in state supplemental benefits as of January 1985, taken from the 1985 Green Book, and the classification of those states paying benefits exceeding 20 percent of the federal level. ${ }^{17}$

Demographic variables in the analysis include race (black or non-black), marital status (married spouse present, never married, and ever married), and education (less than high school, high school

\footnotetext{
${ }^{17}$ There are two additional complications with the benefits reported in the Green Book. First, in two states (California and Wisconsin) SSI recipients are denied food stamps, and the cash value of food stamps for which they would be eligible is instead added to SSI benefits. However, even after adjusting the reported maximum benefits downward to account for the food stamp component, both of these states pay benefits exceeding 20 percent of the federal benefit, the threshold we use for defining generous benefits in some specifications. Second, for two states (Connecticut and Illinois) benefits are decided on a case-by-case basis, and the Green Book reports that the maximum benefit is simply an estimate provided by a state official. To avoid problems from misclassifying these states with respect to generosity of benefits, we also report some results when observations from these two states
} 
graduate, some college, and college graduate).

\section{The Empirical Approach}

We are interested in estimating the effects of the potential receipt of SSI benefits on saving and labor supply. For now, we generically denote these dependent variables as Y, but refer to saving in the discussion, since the empirical work focuses mainly on this variable. Two factors influence the potential value of SSI benefits: the level of the benefits, and the likelihood of receiving them. Thus, for example, we might expect a person with characteristics associated with low permanent income (such as low education), in a state with high SSI benefits, to be most likely to respond by reducing saving. In contrast, a white, married college graduate is extremely unlikely to be eligible for SSI, whether he resides in a state with high or low benefits.

We begin by examining what the data say about the effects of SSI based solely on variation in the probability of being eligible for SSI. By studying workers over age 65, we can identify characteristics associated with a high likelihood of SSI participation. We then distinguish among workers under age 65 based on these characteristics, defining a dummy variable "Part" to equal one for likely participants (in most specifications, based on a chosen threshold for the estimated probability of participating upon reaching age 65), and zero otherwise. ${ }^{18}$ To test our hypothesis, we first estimate an equation of the form:

$$
\mathrm{Y}=\alpha \cdot \text { Part·Age4049 }+\beta \cdot \text { Part } \cdot \text { Age5059 }+\gamma \cdot \text { Part·Age6064 }+\delta+\eta \cdot \text { Age5059 }+\theta \cdot \text { Age6064 }+\varepsilon,
$$

where the age variables are dummy variables for the indicated ranges, and the sample includes individuals aged 40-64. This can be thought of as a "federal experiment"; state benefit levels do not enter because we do not use them to construct Part. The estimates of $\alpha, \beta$, and $\gamma$ indicate differences in saving between individuals likely to be eligible for SSI, and those unlikely to be eligible. For example, $\gamma$ measures the

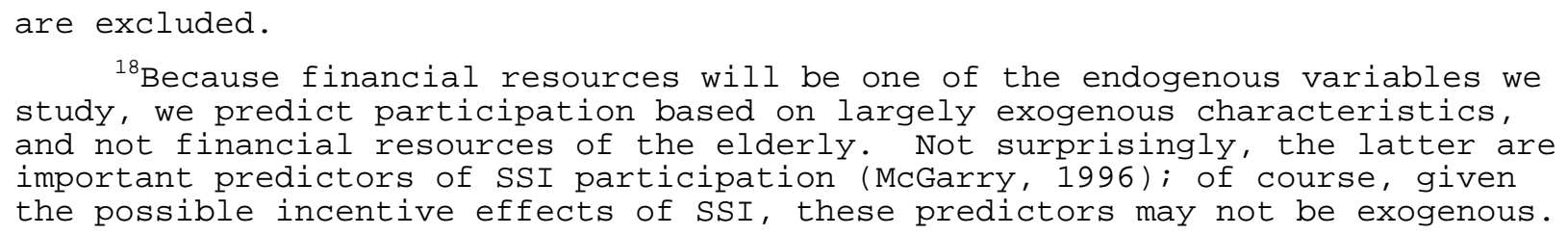


behavioral difference between 60-64 year-olds likely to be eligible and those unlikely to be eligible $\left(\left.\mathrm{Y}\right|_{\text {Part=1,Agec064=1 }}-\left.\mathrm{Y}\right|_{\text {Part=0,Agec6064=1 }}\right)$, and $(\gamma-\alpha)$ measures the difference in the change in $\mathrm{Y}$ from ages 40-49 to ages

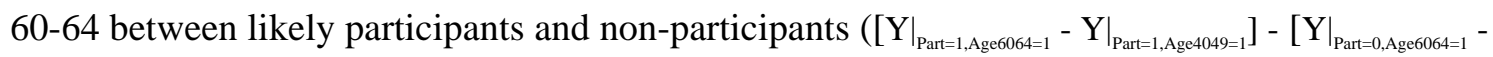

$\left.\left.\left.\mathrm{Y}\right|_{\text {Part }=0, \text { Age } 4049=1}\right]\right)$. If SSI reduces saving of likely participants, we should find $\gamma<0$, because likely participants are predicted to save less, and $(\gamma-\alpha)<0$, because the dissaving of likely participants should accelerate as they approach the age of eligibility for SSI.

We focus mostly on estimates of $\gamma$ or $(\gamma-\alpha)$--rather than $\beta,(\beta-\alpha)$, etc.--because, for a number of reasons, we expect the effects of SSI to be strongest for older workers. First, given stochastic influences on wealth and earnings, older workers can form better predictions of post-retirement assets and income. Second, we suspect that workers pay more attention to the potential receipt of SSI benefits as they approach the age of eligibility. Finally, with respect to saving in particular, because the asset limit rules do not preclude rapid dissaving near the age of eligibility (although they do prohibit asset transfers), younger individuals are more likely to maintain higher asset levels for precautionary reasons, and only to run them down near the age of eligibility. Hence, in the ensuing discussion, we focus on estimates of the effects of SSI on changes in behavior as individuals approach retirement, although the other parameters are reported. In addition, $(\gamma-\alpha)$ is identified from differences in behavior across cohorts, which requires the assumption of constant behavior across cohorts. In contrast, identification of $\gamma$ does not require this assumption. We therefore focus much more on estimates of $\gamma .^{19}$

Of course, while the estimates of $\alpha, \beta$, and $\gamma$ in equation (1) could represent the effects of the SSI program, the estimates are based on a rather tenuous identifying assumption--namely, that in the absence of the program the saving behavior of households with men with characteristics associated with SSI participation would be the same as those of other households. That is, the group for which Part $=0$ (for example, highly-educated men) serves as the "control group" for the estimation of the effects of SSI. It

\footnotetext{
${ }^{19}$ Attanasio (1993) presents evidence of differences in savings profiles across cohorts born between 1925 and 1939, cohorts that largely coincide with
} 
seems likely, however, that age profiles of saving differ systematically with variables such as education, marital status, and race, regardless of the existence or level of SSI benefits. In this case, estimation of equation (1) will lead to biased estimates of the effects of SSI.

This is the reason we exploit state-level variation in the provision of SSI benefits. Individuals in states without state supplementation of SSI benefits, but with characteristics associated with SSI receipt, serve as a much more compelling control group with which to compare the behavior of individuals in states with state supplementation, and with characteristics associated with SSI receipt. At the same time, state-specific saving profiles may also differ in ways that are correlated with SSI benefits. Therefore, we want to identify the effects of SSI from differences between the behavior of likely participants in supplement and non-supplement states and the behavior of unlikely participants in these two types of states, using the unlikely participants to control for these state differences.

Thus, rather than using equation (1), we use a difference-in-difference framework that identifies the effects of SSI from the difference--between states that do and do not supplement SSI--in the difference between individuals likely to participate in SSI, and individuals unlikely to participate in SSI. For example, older high school dropouts (who are much more likely to be SSI participants) may save less than older more-educated workers. But the difference-in-difference framework only infers an effect of SSI if the difference between the saving of older high school dropouts and older more-educated workers is larger in states that supplement SSI than in states that do not.

One simple way to think about the approach is to divide states into those that do and do not supplement SSI. We then estimate equation (1) only for the subset of states that do not supplement SSI, and a similar equation

$$
Y=\alpha^{\prime} \cdot \text { Part Age4049 }+\beta^{\prime} \cdot \text { Part } \cdot \text { Age5059 }+\gamma^{\prime} \cdot \text { Part } \cdot \text { Age6064 }+\delta^{\prime}+\eta^{\prime} \cdot \text { Age5059 }+\theta^{\prime} \cdot \text { Age6064 }+\varepsilon^{\prime},
$$

for the states that supplement SSI. Estimates for these two subsamples provide the relevant difference-in-

the age groups that we study in this paper. 
difference estimates. For example, focusing on 60-64 year-olds, $\gamma^{\prime}$ and $\gamma$ each measure the difference in behavior of likely vs. unlikely participants within a particular type of state (i.e., high- and low-supplement states). $\gamma$ serves as the "baseline" difference in behavior of those with characteristics associated with participation in SSI, and therefore $\left(\gamma^{\prime}-\gamma\right)$ captures the effect of SSI supplements on the saving of likely participants.

Note that, as discussed above, this framework allows the age profile of saving for the population as a whole in a state (captured in $\delta, \eta$, and $\theta$, or $\delta^{\prime}, \eta^{\prime}$, and $\theta^{\prime}$ ) to differ between states that do and do not supplement SSI. This is potentially important to control for biases that might arise from a relationship between policy and other sources of variation in the level or age distribution of $\mathrm{Y}$ in a state (for example, if states in which individuals have greater wealth or higher saving tend to offer more generous SSI supplements). This can be thought of as the analogue to introducing fixed state effects, capturing the relationship between policy and the distribution of $\mathrm{Y}$ that arises for reasons other than responses of the likely participants; because we have a single cross section, we model these state effects in a more restrictive fashion than introducing state dummy variables.

However, differences between $(\delta, \eta$, and $\theta)$ and $\left(\delta^{\prime}, \eta\right.$ ', and $\left.\theta^{\prime}\right)$ could also reflect effects of state differences in the tax treatment of wealth. If such differences reduce saving of the relatively affluent in the same states that offer generous SSI benefits, then difference-in-difference estimates of the effects of SSI on saving will be biased against finding dissaving effects. We examine evidence on this issue below. While we report some estimates of equations (1) and (2) to clarify the approach, we rely more heavily on difference-in-difference estimates from an interactive specification estimated for the pooled sample of states, of the form:

$$
\begin{aligned}
& Y=\alpha \cdot \text { Part·Age4049 }+\beta \cdot \text { Part·Age5059 }+\gamma \cdot \text { Part·Age6064 }+\delta+\eta \cdot \text { Age5059 }+\theta \cdot \text { Age6064 } \\
& +\alpha^{\prime} \cdot \text { Part·Age4049·Supp }+\beta^{\prime} \cdot \text { Part·Age5059·Supp }+\gamma^{\prime} \cdot \text { Part·Age6064·Supp } \\
& +\delta^{\prime} \cdot \operatorname{Supp}+\eta^{\prime} \cdot \operatorname{Age} 5059 \cdot \operatorname{Supp}+\theta^{\prime} \cdot \operatorname{Age} 6064 \cdot \operatorname{Supp}+\varepsilon,
\end{aligned}
$$


where for now "Supp" is a dummy variable for generous SSI supplements. In this specification the estimate of $\gamma^{\prime}$ is the difference-in-difference estimate of the effect of SSI on Y for those aged 60-64 (and the estimate of $\left(\gamma^{\prime}-\alpha^{\prime}\right)$ measures the effect on the change in $Y$ from ages 40-49 to ages $\left.60-64\right){ }^{20,21}$ One advantage of the pooled regression is that it lets us easily assess the statistical significance of our difference-in-difference estimates, since the estimates are obtained from a single estimation. When Supp is a continuous measure, $\gamma$, for example, captures the effect of an additional dollar of supplementary state SSI benefits on the difference in saving between likely participants and unlikely participants aged 60-64, relative to states in which supplementary benefits are held constant; a similar interpretation applies to $\left(\gamma^{\prime}-\alpha^{\prime}\right)$

\section{Results}

\section{SSI Participation}

Table 1 reports descriptive statistics for men aged 65 and over, classified by whether or not they are actual SSI participants. ${ }^{22}$ The differences between the two subgroups are notable. The average wealth of participants is about $\$ 2600$, versus more than $\$ 30000$ for non-participants; the medians also reflect a large difference, although median wealth for participants is much lower. ${ }^{23}$ Participants are much more

\footnotetext{
${ }^{20}$ For example, the difference-in-difference parameter capturing the effect of generous state SSI supplementation on the level of Y for likely participants aged 60-64 is 
likely to have less than a high school education, and virtually guaranteed not to be college graduates. They are also more likely to be black, and never married, divorced, widowed, or separated. The table also reveals differences in state SSI supplementation in the states of residence of participants versus non-participants. Surprisingly, perhaps, participants are less likely to reside in states that supplement SSI. This presumably occurs because of greater concentration of SSI recipients in poorer states that are also less likely to supplement benefits. However, participants are more likely to reside in states with generous SSI supplements; for example, the table shows that recipients are more likely to reside in states in which SSI supplements exceed 20 percent of federal benefits (all such figures refer to maximum benefits), and the average maximum benefit in states in which participants reside is somewhat higher than the average benefit facing non-participants. ${ }^{24}$

Table 2 reports results from estimates of probit models for SSI participation. Panel A, which reports the probit estimates for the sample of those aged 65 and over, shows that many of the univariate differentials with respect to SSI participation apparent in Table 1 continue to hold in this multivariate analysis. Specifically, having left school prior to completing high school, and black or never married, are significantly associated with higher probabilities of SSI participation. In column (3) we add a dummy variable for whether the state of residence supplements benefits. Its estimated coefficient is negative, paralleling the negative differential in the univariate analysis in Table 1, but insignificant. But if we include instead a dummy variable for whether the state provides a supplement greater than 20 percent of the federal supplement (column (4)), or a continuous variable for the maximum supplement (column (5)),

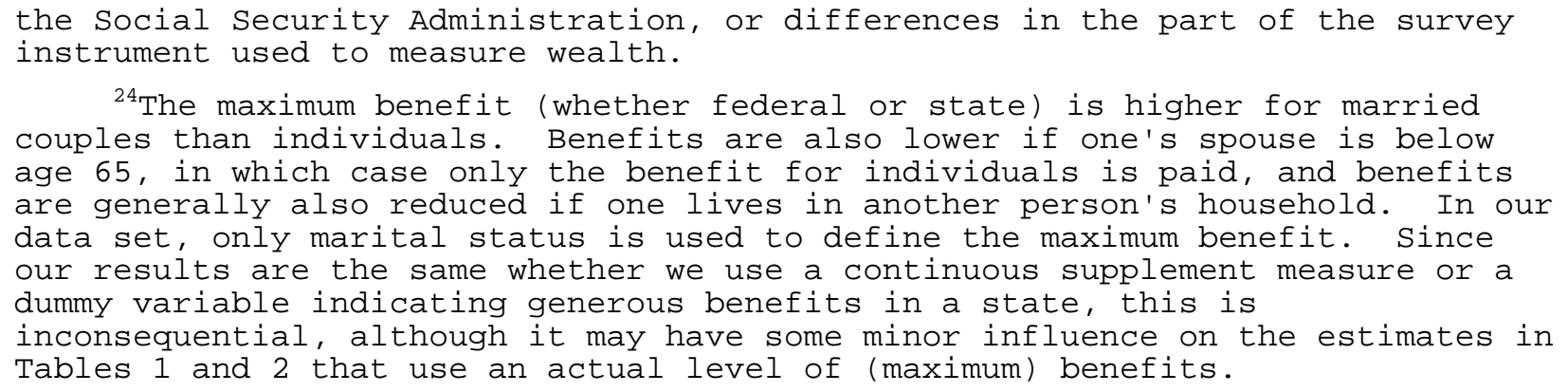


the association with SSI participation is positive and statistically significant. Thus, the generosity of state SSI supplements appears to affect program participation.

The probit estimates in column (2) are used to predict probabilities of participation in SSI for those aged 40-64, to construct the Part variable in equations (1)-(3). Panel B reports on the distribution of these predicted probabilities for this subsample. As the various centiles indicate, the median predicted probability is quite low (about .01), while the predicted probability becomes non-negligible by the 75 th centile, and climbs rapidly between the 90 th and 100th centiles. For most of the results we present, we define Part based on the 75th centile. Based on the proportion of participants among those aged 65 and over, approximately one in five of those above this centile should end up on SSI. It may seem preferable to use a higher cutoff, to isolate the effects of SSI on those who are likely to participate in SSI with much greater certainty. However, using a higher cutoff for Part entails some offsetting influences. On the one hand, the higher probability of participation should induce more dissaving. On the other hand, those with higher probabilities may not engage in nearly as much dissaving, since they may have little accumulated wealth; they may, in fact, not have to engage in any dissaving at all. In other words, the effects of SSI on the extremely poor may be of little interest, if they do not save anyway. Rather, the most interesting question may be whether higher SSI benefits generate dissaving among those with some chance of going on SSI, but who would otherwise accumulate assets above the asset limits. It is the potential disincentive effects for this group that are presumably at the heart of the fears regarding means-tested retirement programs. Nonetheless, in the empirical analysis we also consider evidence using different cutoffs to define likely participants.

\section{Effects on Saving}

Based on some of the results from Table 2, in Table 3 we begin to examine the effects of SSI on saving, now turning to men aged 40-64..$^{25}$ In the first two columns of Panel A, we simply present estimates

\footnotetext{
${ }^{25}$ Of course, the rules of the SSI program may allow conversion of financial assets into other forms of non-counted wealth (such housing, some
} 
of the age profile of savings, for the full sample. Column (1) reports OLS estimates. Because of numerous extremely influential observations, the standard errors of these estimates are huge. Column (2) instead reports median regression (LAD) estimates. The standard errors fall by a factor of 16 or more. Robust (Huber) regressions yielded similar results. Columns (3)-(6) report estimates corresponding to the federal experiment described above. In columns (3) and (4) we classify the men in the sample as likely participants if they failed to complete high school. In columns (5) and (6) we classify them based on estimated probabilities of participation, using the estimated probit model in column (2) of Table 2; this is the fullest specification that does not use information on state supplementation of SSI. We chose an estimated cutoff for the predicted probability of .058 , which covers the 75 th centile of the weighted distribution of predicted probabilities, giving us roughly the same proportion of likely SSI participants based on this classification as we get based on the high-school dropout classification. ${ }^{26}$

The OLS estimates in columns (3) and (5) indicate that likely participants have lower savings in the 60-64 age range. However, the OLS estimates are implausibly large, and again the standard errors are huge. We therefore focus only on the median regression estimates, and in subsequent analyses do not report OLS estimates.

The results of the federal experiment in columns (4) and (6) are quite consistent with the hypothesized dissaving effects of SSI. Whether we classify likely participants based on dropping out of high school, or estimated probabilities of participation, the estimated dissaving effects are negative and significant, and become larger in absolute value as the respondents approach age 65 . By looking at the estimated coefficients of the age dummy variables, we can compare the savings profiles of likely participants and unlikely participants. The estimates in column (4), for example, indicate that men aged

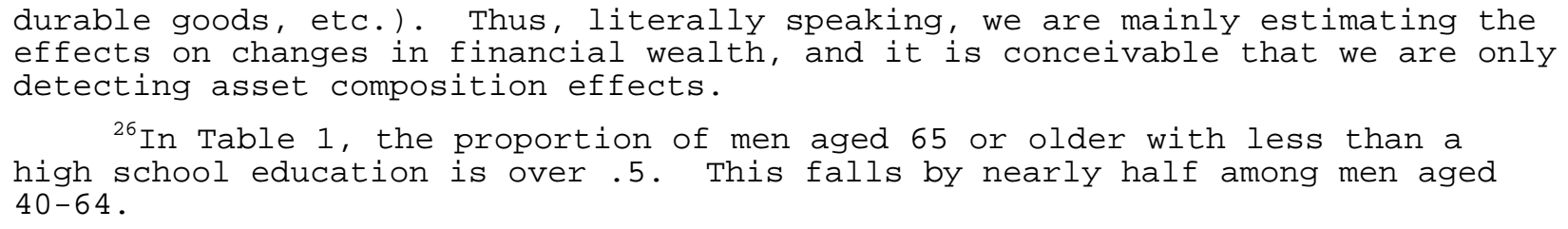


60-64 who are unlikely to participate in SSI save $\$ 1332$ per year $(61+1271)$. Those likely to participate, in contrast, dissave $\$ 1043$ (1332 - 2375). Column (6) yields similar results.

However, as explained in the previous section, while these estimates could reflect the effects of SSI, they may also reflect systematic differences in saving behavior (or initial wealth endowments) based on characteristics associated with participation in SSI. Thus, in Panel B we instead perform a differencein-difference analysis, exploiting the state-level variation in SSI supplementation. As mentioned above, from this point we only report median regression estimates; we also restrict attention to the classification of likely participants based on the estimated probability of participation.

First, column (1) reports estimates of the same equation for individuals in states that do not supplement SSI. These estimates are not very different from those for the full sample in column (6) of Panel A. Column (2) reports estimates for individuals in states that supplement SSI. Recall that the difference between the estimated coefficients of ages 60-64 × likely participant, for example, provides the difference-in-difference estimate of the effect of SSI on savings of those aged 60-64. In this case, this difference is -1443 , which suggests weaker dissaving effects than does the corresponding federal experiment in Panel A.

We saw previously that there may be a qualitative difference between states that provide large supplemental benefits, and those that provide minor supplemental benefits, of which there are many (see Appendix Table A1). Thus, in column (3) we instead report estimates of equation (2) for the subsample residing in states in which state supplements exceed 10 percent of federal benefits. This strengthens the evidence that SSI reduces saving of individuals aged 40-49 and 50-59, but not aged 60-64, as the estimates of $\alpha^{\prime}$ and $\beta^{\prime}$ are more negative (and both significant at the ten-percent level or better) than the corresponding estimates of $\alpha$ and $\beta$ for the non-supplement sample. However, the opposite is true for the estimates of $\gamma$ and $\gamma^{\prime}$. In column (4) we identify a subset of states with more generous supplementation, based on the state supplement exceeding 20 percent of federal benefits, which focuses on a much smaller 
set of states. In this case, the evidence of dissaving effects of SSI is stronger for all age groups, relative to the estimates in column (2). Finally, in column (5) we raise this threshold even higher, to 40 percent, which leaves us with four states in the "treatment" group: California, Colorado, Connecticut, and Massachusetts. For those aged 60-64, these estimates provide even stronger evidence of dissaving effects. Thus, the evidence in Panel B of Table 3 is largely consistent with higher SSI benefits reducing saving among individuals nearing the age of eligibility. Any comparison of states that supplement SSI with states that do not indicates that older men who are likely participants save relatively less in the former than in the latter. Furthermore, the estimated dissaving effect becomes larger the more narrowly we define the treatment group to be those men in states with high state supplementation.

Table 4 turns to a more thorough analysis of the estimated effects of SSI on saving. First, to make interpretation of the results easier, we report results for the fully interactive single equation (3), which lets us directly assess the statistical significance of the difference-in-difference estimates. In this table, we use only the classification of likely participants based on a relatively high estimated probability of participation. In specification (1), we use the 20-percent threshold to classify states that provide generous supplementation. The last estimated coefficient (-2897) is precisely the difference-in-difference estimate (of $\gamma^{\prime}$ ) that we get from a comparison of columns (4) and (1) in Panel B of Table 3. However, now we obtain a standard error for this estimate, and see that it is statistically significant at the ten-percent level.

The first column of Table 5 provides some assistance in interpreting these estimates, by reporting the implied saving for each type of individual classified by age, residence in a supplement or nonsupplement state, and likely participation. The table reveals that the estimated dissaving effect from the difference-in-difference analysis is driven not by differences in saving behavior between likely participants in supplement and non-supplement states, but rather by differences in the saving behavior of unlikely participants in these two types of states, which lead to rather sharp differences between the saving of likely and unlikely participants in supplement states relative to non-supplement states. To see this, note 
that the estimated saving of 60-64 year-old likely participants is actually slightly higher in supplement states than in non-supplement states (90 vs. -33 ). On the other hand, the estimated saving of 60-64 yearold unlikely participants is much higher in supplement states (4696 vs. 1676), leading to a large difference-in-difference estimate of the dissaving effect of generous SSI supplementation $(\{90-(-33)\}$ $\{4696-1676\}=-2897)$. We do not think that the fact that the dissaving effect is driven by saving differences among unlikely participants renders the evidence invalid. However, it is important to understand the source of the effect that we identify, and we would not dispute the argument that the evidence would be stronger if qualitative evidence of dissaving emerged whether or not we differenced out the saving behavior of unlikely participants. Most importantly, though, this evidence implies that it is very important to control for other possible sources of differences in savings behavior between likely and unlikely participants that differ across states--such as the tax treatment of wealth discussed above--to be more confident that we are picking up effects of the SSI program. Intuitively, the difference-in-difference estimation relies on the assumption that--aside from the effects of SSI supplements--there are commonalities in the behavior of individuals within a state, whether they are likely or unlikely participants; this assumption is more plausible to the extent that we have controlled for sources of differences between likely and unlikely participants within a state.

We now turn to more detailed analysis of the difference-in-difference estimation, with a particular focus on other factors that might differ across states and therefore underlie our estimated dissaving effects of SSI. In specification (2) of Table 4 we add demographic control variables. This results in a somewhat weaker estimate of the dissaving effect for those aged 60-64, as the estimate of $\gamma^{\prime}$ falls (in absolute value) and becomes insignificant.

In specification (3) we use the full sample (including those states with supplements less than 20 percent of federal benefits), and employ a continuous measure of the maximum state supplement. While subject to some measurement error, this specification uses more observations and more information. We 
find that the estimated dissaving effect in the 60-64 age range is strong and statistically significant at the five-percent level. To interpret the estimates, column (2) of Table 5 reports the implied saving for each classification of the respondent, evaluated at the mean state supplement for observations in supplement states. In this case, in contrast to the dummy variable specification, saving of likely participants aged 6064 is lower in supplement states than in non-supplement states (215.4 vs. 303). In addition, the difference between the estimated saving of unlikely participants aged 60-64 in supplement and non-supplement states is smaller (3982.4 - 2050 vs. 4696 - 1676). Nonetheless, the dissaving effect is still largely driven by covariation between the saving behavior of unlikely participants and the level of the state's supplementation of SSI.

The next two columns consider problems that arise in measuring features of state SSI programs. First, as mentioned earlier, some states choose to administer their own programs, in which case they can set their own eligibility criteria. In specification (4) of Table 4 we report results for the subset of states with federal administration of SSI (based on information in Kahn, 1987), to ensure that we are looking at states with federal administration and therefore identical asset limits. This is potentially important because in a state with asset limits that differ from the federal limits, one can be eligible for the state but not the federal benefit, or vice versa. ${ }^{27}$ As a result, for states with different asset limits, it is difficult to identify the appropriate maximum benefit level. However, the estimates for this subsample are very similar to those for the full sample, although the estimated dissaving effect for 60-64 year-olds is no longer statistically significant, perhaps because of the smaller sample size. Second, as explained earlier, for two states (Connecticut and Illinois) maximum SSI benefits may not be measured well. Hence, in specification (5) of Table 4 we exclude these states; this has virtually no effect on the estimates, and the estimate for 6064 year-olds is statistically significant.

The next issue we consider is the potentially confounding influences of other policies that vary by

\footnotetext{
${ }^{27}$ McGarry (1996) notes that this occurs frequently.
} 
state. We first consider the influence of other means-tested transfer programs, which may have their own asset limits, on the estimates reported so far. Given that a state with high SSI supplements is also likely to offer relatively generous benefits in other transfer programs, it is possible that the dissaving effects of SSI that we find actually reflect responses to resource limits of programs other than SSI for the aged. ${ }^{28}$ These programs might tend to be used by older individuals because of declining health (increasing the probability of qualifying for disability). Thus, specification (6) excludes those individuals who received any income from means-tested transfer programs during the four months covered by the SIPP wave. This should include General Assistance, AFDC (from other individuals living in the household), and disability payments via SSI. This estimation should be largely free from bias from the effects of other transfer programs (including SSI for the disabled). The estimated effects of SSI are similar to those in the other columns, although again the estimated dissaving effect on those aged 60-64 becomes insignificant. However, the similarity of the coefficient estimates suggests that our estimates of the effects of SSI do not confound effects of asset limits of transfer programs other than SSI for the aged. In specification (7) we instead omit all individuals who report a disability that impairs their ability to work. Such a disability may make them eligible for SSI for the disabled, which raises the same problem as do other transfer programs. In addition, because disabilities may have profound effects on wealth and saving, it is useful to sort out such effects from those that may be induced by SSI, by looking at the population that does not report such a disability. These estimates indicate considerably stronger dissaving effects in the 60-64 age range for this subsample. This may be because SSI benefits for the disabled are closely linked to those for the aged, so disabled individuals in high-supplement states take steps considerably earlier to decumulate assets, generating sharper declines in the 60-64 age range in high-supplement states for the non-disabled.

Next, as discussed in Section II, factors such as the tax treatment of wealth may generate differences between saving behavior of unlikely participants in supplement and non-supplement states,

\footnotetext{
${ }^{28}$ For example, states that offer high SSI supplements for the aged also offer high SSI supplements for the disabled.
} 
hence biasing the difference-in-difference estimates of the effects of SSI supplements. To examine this question, we identify states that have either gift taxes (which tax gifts while living) or estate or inheritance taxes. ${ }^{29}$ It turns out that states with generous supplementation of SSI are overrepresented among the states that do not tax estates, inheritances, or gifts. ${ }^{30}$ If such taxes reduce saving among the wealthy, this may help to explain the higher saving among unlikely participants in supplement states, which Table 5 showed underlies much of the difference-in-difference estimate of the dissaving effect of SSI on likely participants. To examine this possibility, we augmented equation (3) by letting the saving profile differ in states with each of these two types of taxes, adding interactions between the exhaustive set of age dummy variables and two dummy variables: one for gift taxes, and one for estate or inheritance taxes. This should eliminate the influence of differences in the tax treatment of wealth across states. However, as the table shows (specification (8)), this has no effect on the results, as the difference-in-difference estimate of the effect of saving on likely participants aged 60-64 remains negative and statistically significant, with the magnitude little changed. In results not reported in the table, we also included interactions between each of these variables involving tax treatment of wealth and Part, to allow for different effects of the tax treatment of wealth on likely and unlikely participants. While the estimated coefficients of these latter interactions were imprecise, the estimates of $\alpha^{\prime}, \beta^{\prime}$, and $\gamma^{\prime}$--which in this case are identified from differences in saving among those in states that do not impose taxes on estates, inheritances, or gifts--were very similar to those reported for specification (8). In particular, the estimate of $\gamma^{\prime}$ was -12.55 , significant at the ten-percent level.

\footnotetext{
${ }^{29}$ More precisely, with reference to estate taxes, this refers to states that impose more than the federal "pick up" tax, which is the amount of state tax on estates that the federal government permits taxpayers to offset dollarfor-dollar against federal estate taxes. All states impose this pick up tax. (Details are provided in Advisory Commission on Intergovernmental Relations, 1987$.

${ }^{30} 17$ states tax estates or inheritances, and seven tax gifts. Of the 16 states with benefits exceeding ten percent of the federal level, ten are in states that impose no such taxes. Of the seven states with benefits exceeding 20 percent of the federal level, five are in states that impose no such taxes.
} 
We next turn to a specification that experiments with alternative thresholds for classifying respondents as likely participants based on the estimated probability of participation in SSI. In particular, rather than having a single cutoff for the estimated probability of participation in order to be classified as a likely participant, we define three--at the 55th, 75th (as before), and 95th centiles. We then augment equation (3) by introducing the corresponding interactions with the age dummy variables, and with the age and supplement variables. The prediction here is actually ambiguous, as discussed above. On the one hand, those with a higher probability of participation are more likely to pay attention to the incentives created by SSI, since they are more likely to be eligible. On the other hand, they may have little (if any) dissaving to do. The estimates (which come from a single equation) are reported in columns (9)-(9") of Table 4. For those aged 60-64, we actually find that the estimated dissaving effect of SSI rises with the probability of participation used to define likely participants. Moreover, for each of these three cutoffs the estimated dissaving effect is significant at either the five- or ten-percent level. This provides further confirming evidence of a dissaving effect of SSI.

The next two specifications use alternative measures of wealth. First, in specification (10) we exclude equity in vehicles from the definition of wealth used to measure saving; wealth excluding vehicles corresponds more closely to countable wealth if cars are exempt. As the estimates indicate, the qualitative conclusions are the same. The estimate of $\gamma^{\prime}$ is negative and significant at the five-percent level. In fact, when we re-estimated all of the specifications in Table 4 discussed so far using this definition of wealth, the evidence of dissaving effects of SSI was stronger, as the estimates of $\gamma^{\prime}$ were always negative and significant. We chose to report most results using the alternative measure of wealth to present more conservative estimates. In specification (11) we use gross wealth instead of net wealth, so we do not subtract liabilities. We argued earlier that this definition of wealth, while technically closer to countable wealth, gives a misleading indication of the asset position a person is likely to be in when applying for SSI. Regardless, the results are again qualitatively similar, as the estimate of $\gamma^{\prime}$ is negative and significant 
at the ten-percent level. ${ }^{31}$

Finally, to this point we have focused on a dependent variable--saving--that is hypothesized to be affected by the incentives posed by SSI. Generally, we have found evidence of the hypothesized dissaving effects. It is conceivable, however, that other sources of differences in saving or the accumulation of wealth underlie these results. One way to check this is to look at a source of wealth that should not be affected by SSI, and verify that it is not affected. Specifically, in specification (12) we look at the change in housing equity, a variable that might be correlated with other changes in wealth, but should not be influenced by SSI since housing is excluded from countable wealth. As the table shows, there is no evidence that higher SSI supplements are associated with the same kinds of declines in housing wealth that we see when we look at non-housing wealth. ${ }^{32}$ In fact, if anything higher supplements are associated with increased housing wealth in the 40-49 age range, which is consistent with changes in asset composition toward non-counted wealth, although the ages at which this effect appears suggest that it is not the mirror image of the declines in non-housing wealth that occur at older ages.

To summarize, the results based on state-level variation in SSI supplements provide what we regard as rather compelling evidence that SSI for the aged discourages saving among those approaching the age of eligibility. ${ }^{33}$ The evidence is generally statistically significant, the signs of the estimated effects on saving are consistently negative, and the results from a variety of sensitivity analyses often result in the expected changes in the magnitudes of the estimated effects. In addition, we always find larger point estimates of dissaving effects for those nearest the age of eligibility, as we would expect.

\footnotetext{
${ }^{31}$ For both of these alternative definitions of wealth, the statistical evidence of dissaving was stronger using the dummy variable for generous SSI benefits (based on the 20 percent threshold) than using the continuous measure; in both cases the estimate of $\gamma^{\prime}$ was negative and significant at the five-percent level.

${ }^{32}$ Note that here we report robust regression estimates rather than median regression estimates, because of the large spike at zero in the distribution for the change in housing wealth.

${ }^{33}$ If among those individuals who are likely participants, those who save relatively less face higher mortality, there is bias against finding that high SSI benefits reduce saving, as only the higher savers among the likely
} 


\section{Effects on Labor Supply}

As noted earlier, while most of the concern regarding means-tested retirement programs centers on saving, it is also conceivable that such programs affect labor supply, as individuals approaching the age of eligibility have reduced incentives to accumulate pension wealth (including Social Security wealth). However, we find little evidence of such effects. Table 6 reports results from a variety of approaches to this problem. First, column (1) reports estimates of a probit for employment in wave 4, with employment defined as the respondent reporting average usual hours worked per week in wave 4 exceeding zero. The estimate of $\gamma^{\prime}$ measures the difference-in-difference estimate on employment of those aged 60-64. This estimate is negative, consistent with a disemployment effect, but insignificant. A parameter of more interest might be the change in employment from a younger age range to ages 60-64. As an example, the fourth row of the table reports the estimate of $\left(\gamma^{\prime}-\alpha^{\prime}\right)$, which measures the change in employment from ages 40-49 to ages 60-64. This estimate is also negative but statistically insignificant.

Labor supply effects may also show up in hours. Therefore, in column (2) we report Tobit estimates for hours worked (defined as average usual weekly hours in the four months covered by the SIPP wave). The qualitative results are similar to those for employment. In particular, the difference-indifference estimate of the effect of SSI benefits on the hours of likely participants aged 60-64 is negative (-.64) and insignificant, while the effect on the change in hours from ages 40-49 to 60-64 is stronger

\section{$(-1.14)$ but still insignificant.}

While the estimates of $\left(\gamma^{\prime}-\alpha^{\prime}\right)$ attempt to measure changes in behavior as individuals age, these effects of SSI on changes in employment and hours are not identified from actual changes in the behavior of individuals, but rather from differences in behavior across cohorts. A better strategy may be to study changes in individual behavior. In columns (3) and (4) we take a step in this direction by reestimating the

participants survive. (See Jianakoplos, et al., 1989, and Menchik, 1993.) 
employment probit and hours tobit conditioning on past employment or hours. Although a structural interpretation of such equations is problematic, they have the virtue of identifying relatively more of the effect from changes, especially in the case of the tobit where the estimated coefficient on lagged hours is .81 , so we are nearly estimating an equation for the change in hours. These estimates provide even less evidence of an effect of SSI on labor supply, in terms of reductions in labor supply for older workers in the past year, as the estimates of $\gamma^{\prime}$ are actually positive (but small and insignificant). In column (5) we take a similar approach, estimating a probit model for whether hours fell in the past year. Here, the estimated signs of $\gamma^{\prime}$ (and $\beta^{\prime}$ ) are again in the opposite direction of the hypothesized reductions in labor supply, although they are insignificant. Given the lack of any consistent evidence that generous SSI supplements reduce labor supply, we forego the detailed sensitivity analysis that we undertook for saving.

\section{Conclusion}

The goal of this paper is to draw inferences about the potential consequences of means testing Social Security by studying the effects of SSI for the aged, which effectively operates as a means-tested retirement program, in that eligibility depends on financial resources in the form of assets and income. In particular, we examine the effects of SSI on saving and on labor supply at ages near retirement. We primarily use state-level variation in generosity of supplemental SSI payments to identify the effects of SSI, studying a sample of male household heads. We find consistent evidence that SSI reduces the saving of men nearing the age of retirement, which is the anticipated effect of a means-tested retirement program. However, we find no evidence that such programs reduce labor supply of men nearing the age of retirement.

In our view, for a number of reasons these results must be used cautiously both as evidence on the effects of SSI, and as evidence on the likely consequences of means-testing Social Security. With respect to the evidence on the effects of SSI, we think that a more definitive answer awaits additional analyses using other data sets, especially with regard to wealth data for which alternative data sets have adopted 
methods that appear to significantly improve the quality of such data (see, e.g., Smith, 1995).

With respect to using our findings regarding SSI to infer the likely consequences of a means-tested Social Security program, there are three problems. First, the structure of such a program might be sufficiently different from SSI that our results would not generalize. Second, if the alternative to the means-tested program either operates or is perceived to operate very differently from the current Social Security system, behavioral responses to a means-tested program might differ from the responses to SSI that we estimate. Finally, the SSI program serves a poor population, whereas Social Security, even if means tested, would likely continue to serve a higher-income population for which behavioral responses might differ. Obviously, our results speak most directly to proposals that entail a small means-tested program for the needy.

Despite these qualifications, in the absence of the type of information we might be able to obtain following implementation of a means-tested Social Security program, we view our evidence on the potential responses to means-tested Social Security as informative with respect to two issues regarding the effects of such a program. First, such behavioral responses may reflect distortions, given that benefits (and the taxes to pay for them) are not pure lump-sum transfers. If any such distortions reduce economic efficiency, empirical evidence on behavioral responses to means-tested programs may be useful in considering alternative proposals to reform Social Security. For example, Mitchell and Zeldes (1996) advocate a "demogrant" as part of a move to privatize Social Security; this demogrant is a fixed, guaranteed (but small) public pension payment that is not means tested, and hence should avoid many of the disincentive effects of means testing. ${ }^{34}$ Second, proposals to reform Social Security invariably entail projections of revenues and benefits. If individuals respond to means testing by reducing saving, and

\footnotetext{
${ }^{34}$ At the same time, it is important to note that potential distortionary effects of means-tested Social security do not imply that conversion to a fully-funded system (perhaps privatized) for most workers, coupled with a means-tested program for the needy, would result in greater inefficiency, because the conversion of the bulk of the program to fully-funded status may increase efficiency (Feldstein, 1987).
} 
hence increasing the likelihood of being eligible for a means-tested retirement program, such projections are made more complicated. In particular, estimates of the eligible population based on those who currently would qualify for a means-tested program are likely to understate actual eligibility for and participation in a means-tested program, and (depending on the financing) are also likely to overstate revenues.

\section{$\underline{\text { References }}$}

Advisory Commission on Intergovernmental Relations. 1987. Significant Features of Fiscal Federalism 1988 Edition Volume I (Washington, D.C.).

Altig, David, and Jagadeesh Gokhale. 1996. "A Simple Proposal for Privatizing Social Security." Economic Commentary, Federal Reserve Bank of Cleveland, May 1.

Arrau, Patricio, and Klaus Schmidt-Hebbel. 1993. "Macroeconomic and Intergenerational Welfare Effects of a Transition from Pay-as-You-Go to Fully Funded Pensions." Policy Research Department, World Bank, Washington, D. C.

Attanasio, Orazio P. 1993. "A Cohort Analysis of Saving Behavior by U.S. Households." NBER Working Paper No. 4454.

Bipartisan Commission on Entitlement and Tax Reform. 1995. Final Report to the President (Washington, D.C.: Superintendent of Documents.

Burtless, Gary, and Robert A. Moffitt. 1985. "The Joint Choice of Retirement Age and Postretirement Hours of Work.” Journal of Labor Economics, Vol. 3, No. 2, April, pp. 209-36.

Diamond, Peter A. 1996. "Proposals to Restructure Social Security." Journal of Economic Perspectives, Vol. 10, No. 3, pp. 67-88.

Feldstein, Martin. 1995. “Would Privatizing Social Security Raise Economic Welfare?” NBER Working Paper No. 5281.

Feldstein, Martin. 1987. “Should Social Security Benefits Be Means Tested?” Journal of Political Economy, Vol. 95, No. 3, pp. 468-84.

Gramlich, Edward M. 1996. "Different Approaches for Dealing with Social Security." Journal of Economic Perspectives, Vol. 10, No. 3, pp. 55-66.

Gustman, Alan L., and Thomas L. Steinmeier. 1995. "Privatizing Social Security: First Round Effects of a Generic, Voluntary, Privatized U.S. Social Security System.” NBER Working Paper No. 5362. 
Gustman, Alan L., and Thomas L. Steinmeier. 1991. "Changing the Social Security Rules for Work after 65.” Industrial and Labor Relations Review, Vol. 44, No. 4, July, pp. 733-45.

Gustman, Alan L., and Thomas L. Steinmeier. 1986. “A Structural Retirement Model.” Econometrica, Vol. 54, pp. 555-84.

Gustman, Alan L., and Thomas L. Steinmeier. 1984. Modeling the Retirement Process for Policy Evaluation and Research.” Monthly Labor Review, Vol. 107, No. 7, July, pp. 26-33.

Hubbard, Glenn, Jonathan Skinner, and Stephen Zeldes. 1995. "Precautionary Saving and Social Insurance.” Journal of Political Economy, Vol. 103, No. 21, pp. 360-99.

Jianakoplos, Nancy Ammon, Paul L. Menchik, and F. Owen Irvine. 1989. "Using Panel Data to Assess the Bias in Cross-sectional Inferences of Life-Cycle Changes in the Level and Composition of Household Wealth." In Robert E. Lipsey and Helen Stone Tice, eds., The Measurement of Saving, Investment, and Wealth (Chicago: University of Chicago Press), pp. 553-640.

Kahn, Arthur L. "Program and Demographic Characteristics of Supplemental Security Income Recipients, December 1985.” Social Security Bulletin, Vol. 50, No. 5, May, pp. 23-57.

Kotlikoff, Laurence J. 1995. "Privatization of Social Security: How It Works and Why It Matters." NBER Working Paper No. 5330.

McGarry, Kathleen. 1996. "Factors Determining Participation of the Elderly in SSI." Journal of Human Resources, Vol. 31, No. 2, Spring, pp. 331-58.

Menchik, Paul L. 1993. "Economic Status as a Determinant of Mortality Among Black and White Older Men: Does Poverty Kill?" Population Studies, Vol. 47, pp. 427-36.

Mitchell, Olivia S., and Stephen Zeldes. 1996. "Social Security Privatization: A Structure for Analysis." NBER Working Paper No. 5512.

Powers, Elizabeth T. 1996. "Does Means-Testing Welfare Discourage Saving? Evidence from the National Longitudinal Survey of Women.” Federal Reserve Bank of Cleveland.

Powers, Elizabeth T. 1995. "Welfare Participation and Saving: Evidence from Household Data." Federal Reserve Bank of Cleveland.

Scott, Charles G. 1989. "Resources of Supplemental Security Income Recipients." Social Security Bulletin, Vol. 52, No. 8, August, pp. 2-9.

Smith, James P. 1995. "Racial and Ethnic Differences in Wealth in the Health and Retirement Study." Journal of Human Resources, Vol. 30, Supp., pp. S158-83.

Social Security Administration. 1985. "The Supplemental Security Income Program for the Aged, Blind, and Disabled: Characteristics of State Assistance Programs for SSI Recipients." U.S. Department of Health and Human Services.

Zedlewski, Sheila R., and Jack A. Meyer. 1989. Toward Ending Poverty among the Elderly and Disabled through SSI Reform (Washington, D.C.: The Urban Institute Press). 
SSI

$\underline{\text { Participants }}$

(1)
SSI

Non-participants

(2)

Total net wealth

excluding housing

Mean

2577.3

30767.0

(8835.6)

(42475.4)

Median

500

30239

State supplements

.43 .53

SSI benefits

Maximum state SSI

supplement $>20 \%$ of

federal benefit

Maximum SSI

372.4

benefits, individual

(71.2)

364.7

Maximum SSI

595.3

benefits, couple

(178.3)

562.7

(133.8)

.88 .51

.08 .26

High school graduate

.02 .11

Some college

.01 .13

College graduate

.23 .06

Black

.11 .04

Never married

.27 .19

separated/spouse absent

$\mathrm{N}$

98

1850

Means are reported, with standard deviations in parentheses. Data are from Waves 4 and 5 of the 1984 SIPP panel. The wealth measures and other variables are sometimes imputed, but the SIPP does not provide imputation flags for the variables we use. Wealth is measured as of Wave 4. Maximum SSI benefits is combined federal and state, obtained from the 1985 Green Book, and is based on current marital status. Classification of states providing supplements higher than $20 \%$ of the federal benefit is based on whether the supplement for either an individual or a couple exceeds this amount. All estimates are weighted. 


\section{A. Probit Estimates for Male Household Heads Aged 65 and Over}

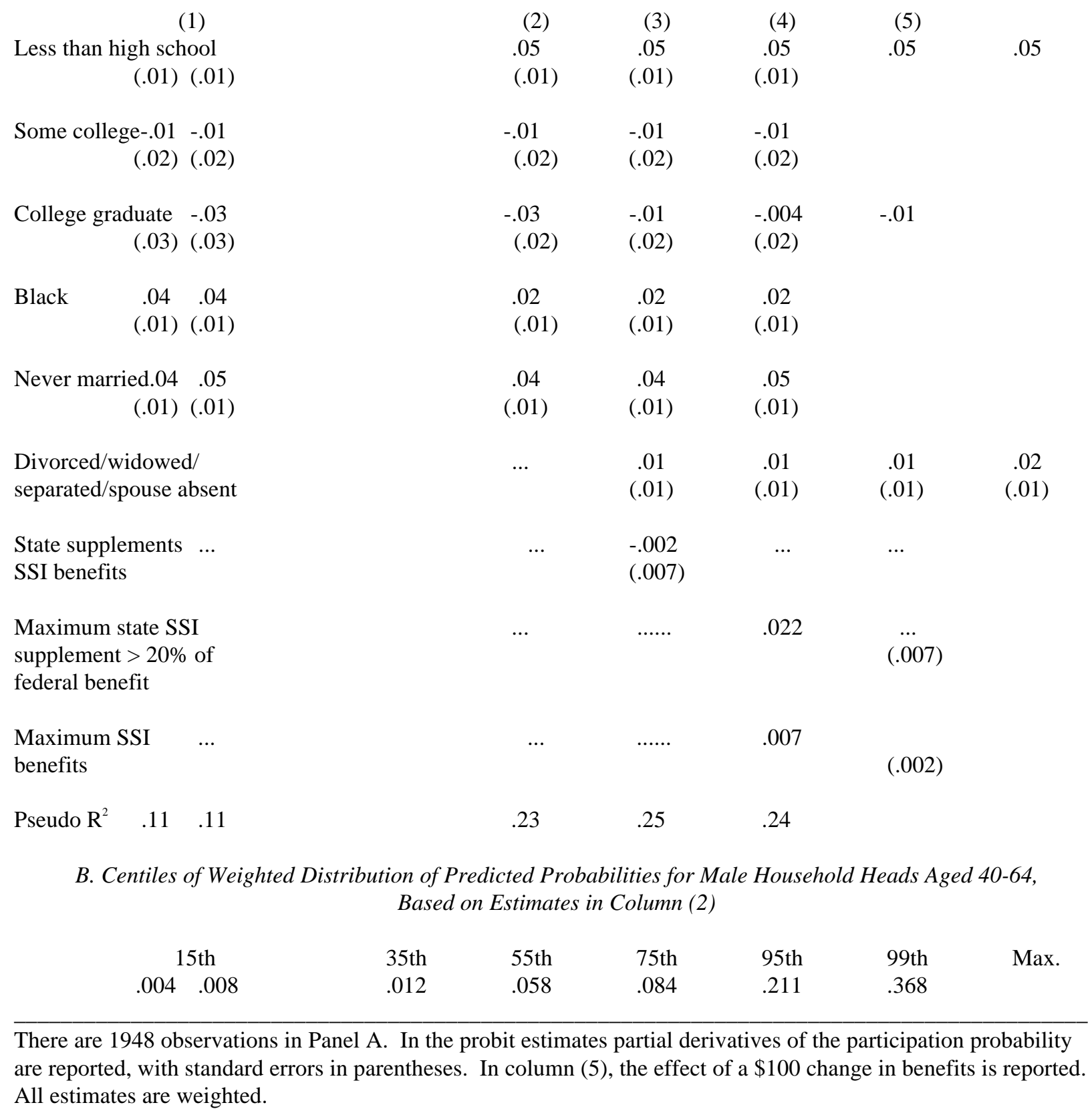


Table 3: OLS and Median Regression Estimates of Effects of SSI on Saving of Likely Participants,

\section{A. Savings Profiles for Full Sample}

$\underline{\text { Single profile }} \underline{\text { Single profile }}$

\begin{tabular}{|c|c|c|c|c|c|c|}
\hline & (1) & (2) & (3) & (4) & (5) & (6) \\
\hline Estimator & OLS & Median & OLS & Median & OLS & Median \\
\hline $\begin{array}{l}\text { Age } 40-49 \\
\times \text { likely participant }\end{array}$ & $\ldots$ & $\ldots$ & $\begin{array}{c}3421.9 \\
(13743.1)\end{array}$ & $\begin{array}{l}-1223 \\
(551.3)\end{array}$ & $\begin{array}{c}3293.7 \\
(13751.1)\end{array}$ & $\begin{array}{l}-1260 \\
(545.6)\end{array}$ \\
\hline $\begin{array}{l}\text { Age } 50-59 \\
\times \text { likely participant }\end{array}$ & $\ldots$ & $\ldots$ & $\begin{array}{c}20684.7 \\
(13249.0)\end{array}$ & $\begin{array}{l}-1332 \\
(529.6)\end{array}$ & $\begin{array}{c}22945.8 \\
(13181.4)\end{array}$ & $\begin{array}{l}-1360 \\
(532.2)\end{array}$ \\
\hline $\begin{array}{l}\text { Age } 60-64 \\
\times \text { likely participant }\end{array}$ & $\ldots$ & $\ldots$ & $\begin{array}{l}-14070.8 \\
(17989.2)\end{array}$ & $\begin{array}{l}-2375 \\
(712.1)\end{array}$ & $\begin{array}{l}-12000.2 \\
(17922.5)\end{array}$ & $\begin{array}{l}-2328 \\
(711.8)\end{array}$ \\
\hline Intercept & $\begin{array}{c}2653.3 \\
(5497.1)\end{array}$ & $\begin{array}{l}725 \\
(259.2)\end{array}$ & $\begin{array}{c}1969.0 \\
(6145.8)\end{array}$ & $\begin{array}{c}61 \\
(377.9)\end{array}$ & $\begin{array}{l}1972 \\
(6171.9)\end{array}$ & $\begin{array}{l}1287 \\
(249.3)\end{array}$ \\
\hline Age 50-59 & $\begin{array}{r}-16116.0 \\
(8104.6)\end{array}$ & $\begin{array}{l}685 \\
(481.6)\end{array}$ & $\begin{array}{r}-21244.3 \\
(9332.6)\end{array}$ & $\begin{array}{l}1354 \\
(504.3)\end{array}$ & $\begin{array}{r}-21991.6 \\
(9367.0)\end{array}$ & $\begin{array}{l}1338 \\
(509.0)\end{array}$ \\
\hline Age $60-64$ & $\begin{array}{c}8398.3 \\
(10245.7)\end{array}$ & $\begin{array}{l}725 \\
(259.2)\end{array}$ & $\begin{array}{c}14178.4 \\
(12448.7)\end{array}$ & $\begin{array}{l}1271 \\
(247.3)\end{array}$ & $\begin{array}{c}13501.1 \\
(12507.9)\end{array}$ & $\begin{array}{c}93 \\
(380.8)\end{array}$ \\
\hline Adjusted/Pseudo $\mathrm{R}^{2}$ & .001 & .000 & .001 & .001 & .001 & .001 \\
\hline $\mathrm{N}$ & 3663 & 3663 & 3663 & 3663 & 3663 & 3663 \\
\hline
\end{tabular}

Likely participants based on Likely participants based on less than high school education: estimated prob. of participation:

(4) (5) (6)

B. Savings Profiles for Supplement vs. Non-Supplement States,

Likely Participants Classified on Basis of High Probability of Participation, Median Regressions

\begin{tabular}{|c|c|c|c|c|}
\hline $\begin{array}{l}\text { State does not } \\
\text { supplement } \\
\text { benefits }\end{array}$ & $\begin{array}{c}\text { State } \\
\text { supplements } \\
\text { benefits }\end{array}$ & $\begin{array}{c}\text { Max. state } \\
\text { supplement }>10 \% \\
\text { of federal benefit }\end{array}$ & $\begin{array}{c}\text { Max. state } \\
\text { supplement }>20 \% \\
\text { of federal benefit }\end{array}$ & $\begin{array}{c}\text { Max. state } \\
\text { supplement }>40 \% \\
\text { of federal benefit }\end{array}$ \\
\hline (1) & (2) & (3) & (4) & (5) \\
\hline $\begin{array}{l}-552 \\
(683.6)\end{array}$ & $\begin{array}{r}-1775 \\
(880.6)\end{array}$ & $\begin{array}{r}-1639 \\
(939.3)\end{array}$ & $\begin{array}{l}-2157 \\
(1339.8)\end{array}$ & $\begin{array}{l}-2267.6 \\
(2167.6)\end{array}$ \\
\hline $\begin{array}{r}-1488 \\
(674.2)\end{array}$ & $\begin{array}{l}-900 \\
(847.3)\end{array}$ & $\begin{array}{r}-1766 \\
(927.9)\end{array}$ & $\begin{array}{l}-1113 \\
(1409.8)\end{array}$ & $\begin{array}{c}-78 \\
(2303.3)\end{array}$ \\
\hline $\begin{array}{l}-1709 \\
(928.6)\end{array}$ & $\begin{array}{l}-3152 \\
(1106.5)\end{array}$ & $\begin{array}{l}-2337 \\
(1187.0)\end{array}$ & $\begin{array}{l}-4606 \\
(1671.8)\end{array}$ & $\begin{array}{l}-6473 \\
(2910.2)\end{array}$ \\
\hline $\begin{array}{c}579 \\
(337.8)\end{array}$ & $\begin{array}{l}1825 \\
(374.7)\end{array}$ & $\begin{array}{l}1659 \\
(400.6)\end{array}$ & $\begin{array}{l}2170 \\
(557.7)\end{array}$ & $\begin{array}{l}2170 \\
(882.2)\end{array}$ \\
\hline $\begin{array}{l}1097 \\
(523.4)\end{array}$ & $\begin{array}{l}-925 \\
(566.8)\end{array}$ & $\begin{array}{c}107 \\
(605.3)\end{array}$ & $\begin{array}{l}-677 \\
(836.0)\end{array}$ & $\begin{array}{l}-1697 \\
(1316.6)\end{array}$ \\
\hline $\begin{array}{l}1097 \\
(706.1)\end{array}$ & $\begin{array}{l}2074 \\
(751.1)\end{array}$ & $\begin{array}{l}1241 \\
(798.9)\end{array}$ & $\begin{array}{c}2526 \\
(1125.1)\end{array}$ & $\begin{array}{l}4600 \\
(1843.8)\end{array}$ \\
\hline .001 & .001 & .001 & .001 & .001 \\
\hline 1655 & 2008 & 1559 & 694 & 522 \\
\hline
\end{tabular}

1559
Age 40-49

$\times$ likely participant

Age 50-59

$\times$ likely participant

Age 60-64

$\times$ likely participant

Intercept

Age 50-59

Age 60-64

Pseudo $\mathrm{R}^{2}$

$\mathrm{N}$

Saving is measured as the change in total net wealth excluding housing from Wave 4 to Wave 7 . All regressions also include an intercept.

Probability of SSI participation is based on estimates of the probit model in column (2) of Table 2. Likely participants in columns (5) and (6) of Panel A, and "High probability of participation" in Panel B, indicates observations with predicted probability exceeding .058, which is the 75th 
centile of the weighted distribution of estimated probabilities. "Maximum state supplement" refers to supplement for either a couple or an individual (i.e., the maximum percentage). All estimates are weighted. 
Table 4: Difference-in-Difference Estimates of Effects of SSI on Saving of Likely Participants,

Male Household Heads Aged 40-64, Median Regressions

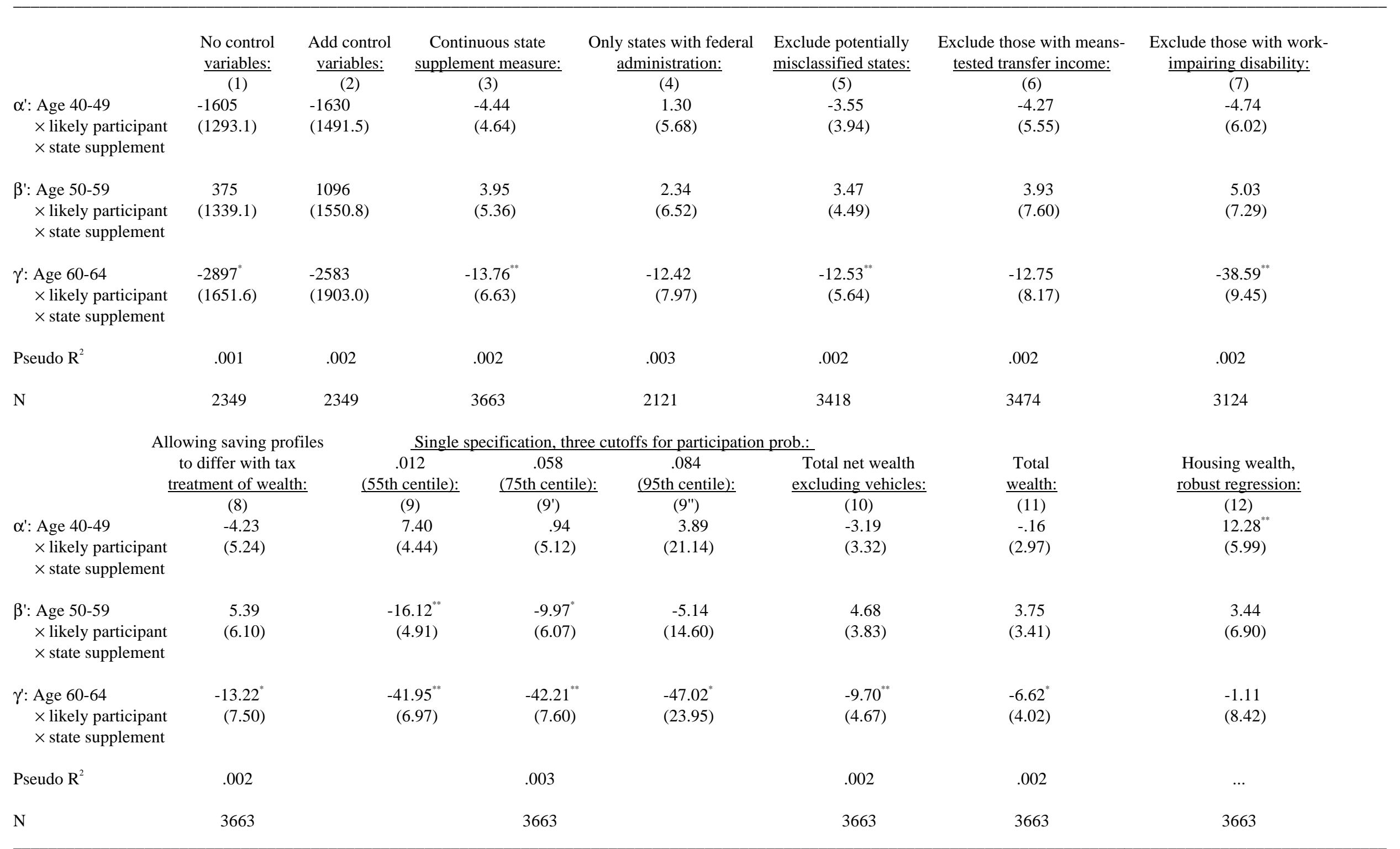

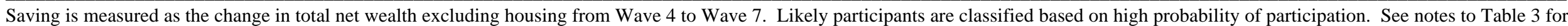

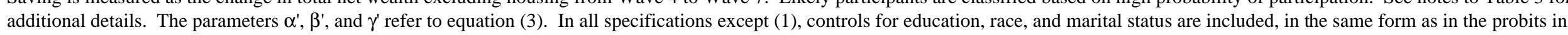

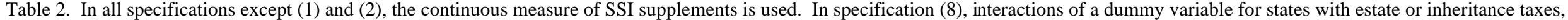

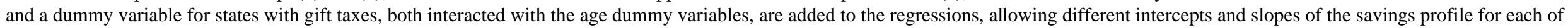

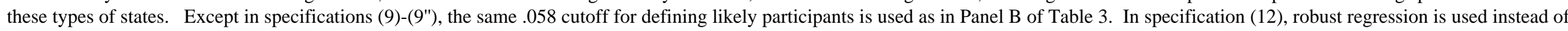

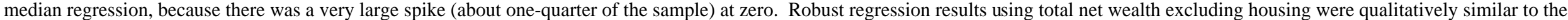

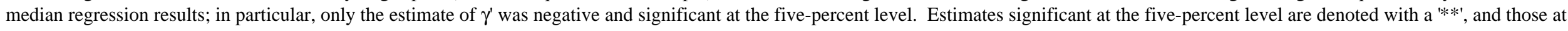


the ten-percent level with a '*'. All estimates are weighted except specification (12). 


\begin{tabular}{|c|c|c|}
\hline & $\begin{array}{c}\text { Using dummy variable for } \\
\text { supplement }>20 \% \text { of federal benefit: }\end{array}$ & $\begin{array}{c}\begin{array}{c}\text { Using continuous } \\
\text { supplement measure: }\end{array} \\
\text { (2) }\end{array}$ \\
\hline $\begin{array}{l}\text { Likely participant, age } 40-49 \text {, } \\
\text { in supplement state }\end{array}$ & 13 & 607.6 \\
\hline $\begin{array}{l}\text { Likely participant, age } 50-59 \text {, } \\
\text { in supplement state }\end{array}$ & 380 & 91.3 \\
\hline $\begin{array}{l}\text { Likely participant, age } 60-64 \text {, } \\
\text { in supplement state }\end{array}$ & 90 & 215.4 \\
\hline $\begin{array}{l}\text { Likely participant, age } 40-49 \text {, } \\
\text { in non-supplement state }\end{array}$ & 27 & 27.2 \\
\hline $\begin{array}{l}\text { Likely participant, age } 50-59 \text {, } \\
\text { in non-supplement state }\end{array}$ & 188 & 0 \\
\hline $\begin{array}{l}\text { Likely participant, age } 60-64 \text {, } \\
\text { in non-supplement state }\end{array}$ & -33 & 303 \\
\hline $\begin{array}{l}\text { Unlikely participant, age } 40-49 \text {, } \\
\text { in supplement state }\end{array}$ & 2170 & 1483.8 \\
\hline $\begin{array}{l}\text { Unlikely participant, age 50-59, } \\
\text { in supplement state }\end{array}$ & 1493 & 1014.5 \\
\hline $\begin{array}{l}\text { Unlikely participant, age } 60-64 \text {, } \\
\text { in supplement state }\end{array}$ & 4696 & 3982.4 \\
\hline $\begin{array}{l}\text { Unlikely participant, age 40-49, } \\
\text { in non-supplement state }\end{array}$ & 579 & 899.0 \\
\hline $\begin{array}{l}\text { Unlikely participant, age 50-59, } \\
\text { in non-supplement state }\end{array}$ & 1676 & 1600 \\
\hline $\begin{array}{l}\text { Unlikely participant, age } 60-64 \text {, } \\
\text { in non-supplement state }\end{array}$ & 1676 & 2050 \\
\hline
\end{tabular}

In column (1), estimates are based on specification (1) from Table 4. In column (2), estimates are based on the same specification as in column (3) of Table 4, excluding the control variables. For this specification the estimates (standard errors) of $\alpha^{\prime}, \beta^{\prime}$, and $\gamma^{\prime}$ were: -4.32 (4.69), 4.96 (5.30), and -14.82 (6.57). Estimates of the saving profiles in states that supplement are based on mean supplement for those states. See notes to Tables 3 and 4 for additional details. 
Table 6: Difference-in-Difference Estimates of Effects of SSI on Labor Supply Measures for Likely Participants, Male Household Heads Aged 40-64

\begin{tabular}{|c|c|c|c|c|c|}
\hline \multirow{4}{*}{$\begin{array}{l}\text { Employment } \\
\text { probit: } \\
\quad(1) \\
\alpha^{\prime}: \text { Age } 40-49 \\
\quad \times \text { likely participant } \\
\quad \times \text { state supplement }\end{array}$} & $\begin{array}{l}\text { Hours } \\
\text { tobit: }\end{array}$ & $\begin{array}{c}\text { Empl. probit } \\
\text { cond. on lagged empl. }\end{array}$ & $\begin{array}{l}\text { Hours tobit, } \\
\text { cond. on lagged hours: }\end{array}$ & $\begin{array}{l}\text { Probit for } \\
\text { reduced hours: }\end{array}$ & \\
\hline & $(2)$ & (3) & (4) & $(5)$ & \\
\hline & .01 & .50 & .02 & 1.01 & -.02 \\
\hline & $(.02)$ & (.97) & $(.02)$ & $(.72)$ & $(.02)$ \\
\hline $\begin{aligned} \beta^{\prime}: & \text { Age } 50-59 \\
& \times \text { likely participant } \\
& \times \text { state supplement }\end{aligned}$ & $\begin{array}{l}-.004 \\
(.01)\end{array}$ & $\begin{array}{c}.11 \\
(1.01)\end{array}$ & $\begin{array}{l}-.01 \\
(.01)\end{array}$ & $\begin{array}{l}-.68 \\
(.76)\end{array}$ & $\begin{array}{l}.005 \\
(.02)\end{array}$ \\
\hline $\begin{aligned} \gamma: & \text { Age } 60-64 \\
& \times \text { likely participant } \\
& \times \text { state supplement }\end{aligned}$ & $\begin{array}{l}-.01 \\
(.02)\end{array}$ & $\begin{array}{c}-.64 \\
(1.33)\end{array}$ & $\begin{array}{l}.02 \\
(.02)\end{array}$ & $\begin{array}{c}.81 \\
(1.01)\end{array}$ & $\begin{array}{l}-.03 \\
(.03)\end{array}$ \\
\hline $\begin{array}{ll}\left(\gamma^{\prime}-\alpha^{\prime}\right) & -.02 \\
& (.02)\end{array}$ & $\begin{array}{l}-1.14 \\
(1.64)\end{array}$ & $\ldots$ & $\ldots$ & $\ldots$ & \\
\hline $\begin{array}{r}\text { Age } 50-59 \\
(.02)\end{array}$ & $\begin{array}{c}-.12 \\
(1.15)\end{array}$ & $\begin{array}{r}-6.24 \\
(.02)\end{array}$ & $\begin{array}{l}-.04 \\
(.85)\end{array}$ & $\begin{array}{r}-2.65 \\
(.02)\end{array}$ & .01 \\
\hline $\begin{array}{r}\text { Age 60-64 } \\
(.02)\end{array}$ & $\begin{array}{c}-.31 \\
(1.53)\end{array}$ & $\begin{array}{r}-22.28 \\
(.02)\end{array}$ & $\begin{array}{c}-.12 \\
(1.17)\end{array}$ & $\begin{array}{r}-9.07 \\
(.03)\end{array}$ & -.02 \\
\hline Lagged employment & $\ldots$ & $(.01)$ & .36 & $\ldots$ & $\ldots$ \\
\hline Lagged hours & $\ldots$ & $\ldots$ & $\begin{array}{l}\ldots \\
(.02)\end{array}$ & .81 & $\ldots$ \\
\hline $\begin{array}{l}\text { Adjusted R-squared/ } \\
\text { Pseudo R-squared }\end{array}$ & .15 & .02 & .54 & .10 & .01 \\
\hline N 3257 & 3257 & 3178 & 3178 & 3178 & \\
\hline
\end{tabular}

See notes to Table 3 for details. Likely participants are classified based on high probability of participation. The parameters $\alpha^{\prime}, \beta^{\prime}$, and $\gamma^{\prime}$ refer to equation (3). The estimated coefficients of age 50-59 and age 60-64 correspond to $\eta$ and $\theta$ in equation (3). In columns (1), (3), and (5) partial derivatives of probability are reported, with standard errors in parentheses. All specifications include controls for education, race, and marital status; the variables are entered as in the probits in Table 2. Lagged employment and hours are taken from two waves (eight months) prior. If we instead use data from one year later, there are far more missing observations because the interviewed sample was reduced. The same .058 cutoff for defining likely participants is used as in Table 4 and Panel B of Table 3. The maximum state supplement is defined in terms of 100s of dollars. Estimates significant at the five-percent level are denoted with a '**', and those at the ten-percent level with a '*'. 


\begin{tabular}{|c|c|c|c|}
\hline \multirow{2}{*}{\multicolumn{2}{|c|}{$\frac{\text { State }}{\text { Benefit }}$}} & \multirow[t]{2}{*}{$\underline{\text { Individuals }}$} & \multirow[t]{2}{*}{$\underline{\text { Couples }>20 \% \text { of Federal }}$} \\
\hline & & & \\
\hline Alabama & 0 & 0 & No \\
\hline Arizona & 0 & 0 & No \\
\hline Arkansas & 0 & 0 & No \\
\hline California & 179 & 448 & Yes \\
\hline Colorado & 58 & 278 & Yes \\
\hline Connecticut & 172 & 119 & Yes \\
\hline Delaware & 0 & 0 & No \\
\hline Washington, D.C. & 15 & 30 & No \\
\hline Florida & 0 & 0 & No \\
\hline Georgia & 0 & 0 & No \\
\hline Hawaii & 5 & 9 & No \\
\hline Illinois & 35 & 34 & No \\
\hline Indiana & 0 & 0 & No \\
\hline Iowa & 0 & 0 & No \\
\hline Kansas & 0 & 0 & No \\
\hline Kentucky & 0 & 0 & No \\
\hline Louisiana & 0 & 0 & No \\
\hline Maine & 10 & 15 & No \\
\hline Maryland & 0 & 0 & No \\
\hline Massachusetts & 129 & 202 & Yes \\
\hline Michigan & 27 & 40 & No \\
\hline Minnesota & 35 & 66 & No \\
\hline Missouri & 0 & 0 & No \\
\hline Montana & 0 & 0 & No \\
\hline Nebraska & 61 & 89 & No \\
\hline Nevada & 37 & 74 & No \\
\hline New Hampshire & 27 & 21 & No \\
\hline New Jersey & 31 & 25 & No \\
\hline New York & 61 & 76 & No \\
\hline North Carolina & 0 & 0 & No \\
\hline North Dakota & 0 & 0 & No \\
\hline Ohio & 0 & 0 & No \\
\hline Oklahoma & 60 & 120 & Yes \\
\hline Oregon & 2 & 0 & No \\
\hline Pennsylvania & 32 & 49 & No \\
\hline Rhode Island & 54 & 102 & Yes \\
\hline South Carolina & 0 & 0 & No \\
\hline Tennessee & 0 & 0 & No \\
\hline Texas & 0 & 0 & No \\
\hline Utah & 10 & 20 & No \\
\hline Vermont & 53 & 97 & No \\
\hline Virginia & 0 & 0 & No \\
\hline Washington & 38 & 37 & No \\
\hline Wisconsin & 100 & 161 & Yes \\
\hline
\end{tabular}


Pooled equation:

$$
\begin{aligned}
& Y=\alpha \cdot \text { Part } \cdot \text { Age4049 }+\beta \cdot \text { Part } \cdot \text { Age } 5059+\gamma \cdot \text { Part } \cdot \text { Age6064 }+\delta+\eta \cdot \text { Age } 5059+\theta \cdot \text { Age6064 } \\
& +\alpha^{\prime} \cdot \text { Part·Age4049·Supp }+\beta^{\prime} \cdot \text { Part·Age5059·Supp }+\gamma^{\prime} \cdot \text { Part·Age6064·Supp } \\
& +\delta^{\prime} \cdot \operatorname{Supp}+\eta^{\prime} \cdot \text { Age 5059·Supp }+\theta^{\prime} \cdot \text { Age6064·Supp }
\end{aligned}
$$

Estimates:

1 .

$$
\left(\left.\mathrm{Y}\right|_{\text {Supp=1,Part=1,Age6064=1 }}-\left.\mathrm{Y}\right|_{\text {Supp=1,Part=0,Age6064=1 }}\right)-\left(\left.\mathrm{Y}\right|_{\text {Supp=0,Part=1,Age6064=1 }}-\left.\mathrm{Y}\right|_{\text {Supp=0,Part=0,Age6064=1 }}\right)=
$$

Difference-in-difference estimate of effect of state SSI supplement on level of Y for likely participants aged 60-64 = $\left(\gamma+\delta+\theta+\gamma^{\prime}+\delta^{\prime}+\theta^{\prime}-\delta-\theta-\delta^{\prime}-\theta^{\prime}\right)-(\gamma+\delta+\theta-\delta-\theta)=\gamma^{\prime}$

2.

$$
\left\{\left(\left.\mathrm{Y}\right|_{\text {Supp=1,Part=1,Age6064=1 }}-\left.\mathrm{Y}\right|_{\text {Supp=1,Part=1,Age4049=1 }}\right)-\left(\left.\mathrm{Y}\right|_{\text {Supp=1,Part=0,Age6064=1 }}-\left.\mathrm{Y}\right|_{\text {Supp=1,Part=0,Ag4049=1 }}\right)\right\}
$$

$$
-\left\{\left(\left.\mathrm{Y}\right|_{\text {Supp=0,Part=1,Age6064=1 }}-\left.\mathrm{Y}\right|_{\text {Supp=0,Part=1,Age4049=1 }}\right)-\left(\left.\mathrm{Y}\right|_{\text {Supp=0,Part=0,Age6064=1 }}-\left.\mathrm{Y}\right|_{\text {Supp=0,Part=0,Ag4049=1 }}\right)\right\}
$$

Difference-in-difference estimate of effect of state SSI supplement on change in Y for likely participants from age $40-49$ to age $60-64=$

$$
\left\{\left(\gamma+\delta+\theta+\gamma^{\prime}+\delta^{\prime}+\theta^{\prime}-\alpha-\delta-\alpha^{\prime}-\delta^{\prime}\right)-\left(\delta+\theta+\delta^{\prime}+\theta^{\prime}-\delta-\delta^{\prime}\right)\right\}-\{(\gamma+\delta+\theta-\alpha-\delta)-(\delta+\theta-\delta)\}=\gamma^{\prime}-\alpha^{\prime}
$$

$\mathrm{Y}$ is an unconditional expectation. $\left.\mathrm{Y}\right|_{\ldots}$ is a conditional expectation. 